\title{
PENTINGNYA MENUMBUHKAN KEDISIPLINAN UNTUK MENINGKATKAN PRESTASI BELAJAR DI LEMBAGA AMIL ZAKAT NASIONAL MIZAN AMANAH (LAZNAS MIZAN AMANAH) CINERE
}

\author{
Sam Cay, Ading Sunarto, Dewi Sartika, Raden Yeti Sumiaty, M Anton Nurhidayat \\ Dosen Ekonomi Fakultas Ekonomi Universitas Pamulang

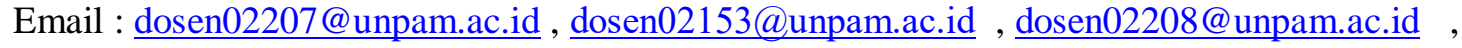 \\ dosen02250@unpam.ac.id , dosen02200@unpam.ac.id
}

\begin{abstract}
ABSTRAK
Penanaman sikap disiplin di rumah hendaknya dimulai sejak usia dini dengan mengajarkan kebiasaan-kebiasaan yang baik pada anak. Kebiasaan-kebiasaan yang ditanamkan oleh orang tua akan terbawa oleh anak dan akan mempengaruhi perilaku kedisiplinanannya. Oleh karena itu orang tua harus melatih anak untuk disiplin belajar sejak usia dini. Sering kita melihat anak- anak pada saat ini banyak yang tidak disiplin dalam belajar. Mereka setiap harinya lebih suka menghabiskan waktu di depan televisi, atau di komputer dibandingkan dengan belajar. Namun, apabila anak sejak usia dini sudah ditanamkan sikap disiplin dalam belajar setiap harinya maka anak akan terbiasa melakukan belajar setiap hari tanpa dipaksa oleh orang tuanya. Dalam kegiatan PKM ini bertujuan untuk mengetahui bagaimana pengaruh kedipslinan terhadap Prestasi belajar pada anak-anak di Lembaga Amil Zakat Nasional Mizan Amanah, Pengabdian Kepada Masyarakat (PKM) ini adalah memberikan sosialisasi serta role play dalam konteks mensosialisasikan bagaimana meningkatkan prestasi belajar pada diri peserta didik di Lembaga Amil Zakat Nasional Mizan Amanah.
\end{abstract}

Kata Kunci : Kedisiplinan Siswa, Prestasi Belajar

\begin{abstract}
ABSTRAC
Cultivating discipline at home should start from an early age by teaching good habits to children. The habits instilled by parents will be carried away by the child and will affect their disciplinary behavior. Therefore, parents must train children to learn discipline from an early age. Often we see children today who are not disciplined in learning. They prefer to spend time in front of the television or on the computer every day than studying. However, if the child from an early age has been instilled in a disciplined attitude in learning every day, the child will get used to learning every day without being forced by their parents. In this PKM activity aims to find out how the influence of discipline on learning achievement in children at the Mizan Amanah National Zakat Institute, Community Service (PKM) is to provide socialization and role play in the context of socializing how to improve learning achievement in students in Mizan Amanah National Zakat Institute.
\end{abstract}

\section{Keywords: Student Discipline, Learning Achievement}

\section{PENDAHULUAN}

Pendidikan pada dasarnya merupakan upaya dari manusia untuk dapat memperoleh pengetahuan dan keterampilan dalam rangka memenuhi kelangsungan hidupnya. Pendidikan merupakan salah satu kebutuhan pokok dalam kehidupan manusia yang memikirkan bagaimana menjalani kehidupan ini untuk mempertahankan hidup manusia yang mengemban tugas dari Sang Kholiq untuk beribadah. Berdasarkan Undang- undang Sisdiknas No. 20 Tahun 2003 Bab I pasal 3, pendidikan adalah: 
Loyalitas Kreativitas Aldi Masyarakat Kreatif
"Usaha sadar dan terencana untuk mewujudkan suasana belajar dan proses pembelajaran agar peserta didik secara aktif mengembangkan potensi dirinya untuk memiliki kekuatan spiritual keagamaan, pengendalian diri, kepribadian, kecerdasan, akhlak mulia, serta keterampilan yang diperlukan bagi dirinya, masyarakat, bangsa dan negara".

Pendidikan harus dilihat dalam cakupan pengertian yang luas. Pendidikan bukan merupakan suatu proses yang netral sehingga terbebas begitu saja dari nilai-nilai dan ideologi. Pendidikan merupakan upaya terorganisir, berencana dan berlangsung kontinu (terus menerus sepanjang hayat) ke arah membina manusia/anak didik menjadi insan paripurna, dewasa dan berbudaya. Pendidikan merupakan upaya terorganisir yang memiliki makna bahwa pendidikan harus dilakukan oleh usaha sadar manusia dengan dasar dan tujuan jelas, ada tahapannya dan ada komitmen bersama didalam proses pendidikan.

Pada dasarnya keberhasilan belajar, dalam hal ini prestasi belajar ditentukan oleh dua faktor yaitu faktor yang berasal dari dalam diri siswa (internal) dan dari luar diri siswa (eksternal). Faktor internal antara lain, faktor jasmani, kecerdasan/intelegensi, kedisiplinan, minat, bakat, motivasi, dan lain-lain. Sedangkan faktor eksternal berasal dari faktor sosial dan faktor non sosial. Faktor sosial mencakup lingkungan keluarga, lingkungan sekolah, dan lingkungan masyarakat. Interaksi dan komunikasi antar individu dalam ketiga lingkungan tersebut mempunyai pengaruh terhadap perilaku dan aktivitas belajar siswa. Jadi tidak ada faktor tunggal yang berdiri sendiri secara otomatis menentukan prestasi belajar seseorang.

Keluarga merupakan salah satu faktor yang berperan dalam keberhasilan belajar. Keluarga adalah tempat yang pertama dan utama bagi anak. Selain itu keluarga juga merupakan fondasi primer tempat anak untuk menghabiskan sebagian besar waktu dalam kehidupannya. Keluarga juga diartikan sebagai suatu satuan sosial terkecil yang dimiliki manusia sebagai makhluk sosial, yang ditandai dengan adanya kerjasama.

Ada beberapa pandangan atau anggapan mengenai keluarga. Menurut Soelaeman dalam Moch shochib (1998: 17) menyatakan bahwa, "keluarga adalah sekumpulan orang yang hidup bersama dan masing-masing anggota merasakan adanya pertautan batin sehingga terjadi saling mempengaruhi, saling memperhatikan, dan saling menyerahkan diri". Sedangkan David (1992: 33) mengkategorikan keluarga dalam pengertian sebagai keluarga seimbang, keluarga kuasa, keluarga protektif, keluarga kacau, dan keluarga simbiotis.

Dari pernyataan diatas menunjukan bahwa suasana iklim yang kondusif dalam keluarga adalah kebersamaan dan kasih sayang dalam lingkungan pribadi setiap anggotanya, terutama bagi pertumbuhan dan perkembangan dalam hal pembentukan sikap dan perilakunya sehari-hari. Dalam pembentukan dan perkembangan kepribadian masa kanak-kanak di lingkungan keluarga yang kondusif mempunyai peranan yang sangat penting dalam pembentukan dasar kepribadian dan identitas pribadi seseorang.

Keseimbangan didalam kehidupan keluarga perlu dipupuk dan di jaga. Masing-masing anggota keluarga hendaknya mengetahui tugas, kewajiban, dan tanggung jawabnya. Orang tua (ayah dan ibu) memiliki peranan yang penting dalam menciptakan keseimbangan hubungan yang harmonis di dalam keluarga. Dengan tanggung jawabnya, orang tua sangat berperan di dalam mengantarkan keberhasilan anak dalam pendidikan. Dikatakan demikian karena apabila suatu keluarga itu harmonis yang di dalamnya terdapat hubungan yang nyata, teratur dan baik, terutama hubungan anak dengan orang tua, maka intensitas orang tua dalam membimbing anak untuk belajar akan meningkat.

Latar belakang lingkungan keluarga yang harmonis akan mengantarkan anak untuk mencapai cita-citanya. Demikian pula sebaliknya, lingkungan keluarga yang tidak baik atau yang tidak harmonis akan sulit untuk membimbing anak-anaknya menjadi yang terbaik untuk masa depannya. Karena keluarga yang tidak harmonis akan membentuk karakter dan kepribadian anak yang tidak baik pula. Anak yang tumbuh dari keluarga yang kacau akan tumbuh menjadi anak yang nakal dan suka membuat kekacauan. Hal ini disebabkan karena dalam 
Loyalitas Kreativitas Aldi Masyarakat Kreatif lingkungan keluarganya anak-anak tidak mendapatkan perhatian dan bimbingan yang baik oleh orang tuanya.

Di sekolah sering kita jumpai anak melakukan pelanggaran yang dilakukan oleh siswa. Misalnya sering membolos, terlambat datang ke sekolah, sering membuat keributan, dan pelanggaran lainnya yang disebabkan rendahnya tingkat disiplin diri siswa. Untuk mengatasinya sekolah membuat peraturan beserta sanksi apabila peraturan tersebut tidak dilaksanakan, sehingga siswa benar-benar mentaati peraturan. Banyak siswa yang benar- benar mentaati peraturan tersebut, namun juga tidak sedikit yang tidak mentaatinya.

Timbulnya sikap disiplin bukan merupakan peristiwa dadakan yang terjadi seketika tanpa perlu adanya pembiasaan. Penanaman disiplin memerlukan proses dan latihan yang cukup lama. Pengenalan dan penanaman sikap disiplin belajar pada anak dapat dilakukan di rumah dan di sekolah. Penanaman sikap disiplin di rumah hendaknya dimulai sejak usia dini dengan mengajarkan kebiasaan- kebiasaan yang baik pada anak. Kebiasaan-kebiasaan yang ditanamkan oleh orang tua akan terbawa oleh anak dan akan mempengaruhi perilaku kedisiplinanannya. Oleh karena itu orang tua harus melatih anak untuk disiplin belajar sejak usia dini. Sering kita melihat anak- anak pada saat ini banyak yang tidak disiplin dalam belajar. Mereka setiap harinya lebih suka menghabiskan waktu di depan televisi, atau di komputer dibandingkan dengan belajar. Namun, apabila anak sejak usia dini sudah ditanamkan sikap disiplin dalam belajar setiap harinya maka anak akan terbiasa melakukan belajar setiap hari tanpa dipaksa oleh orang tuanya.

Dengan memberikan tata tertib dan pengawasan terhadap pelaksanaanya serta penjelasan- penjelasan terhadap arti pentingnya kedisiplinan diharapkan akan dapat menumbuhkan rasa disiplin siswa. Sehingga dengan terciptanya kedisiplinan di sekolah akan mendukung proses kegiatan belajar mengajar yang ada dan dengan proses belajar yang sesuai dengan kurikulum dan tujuan yang hendak dicapai diharapkan dapat meningkatkan prestasi belajar dalam lembaga
Lembaga Amil Zakat Nasional Mizan Amanah (Laznaz Mizan Amanah).

\section{RUMUSAN MASALAH}

Adapun perumusan masalah adalah pada PKM ini adalah:

1. Bagaimana Kedisiplinan para peserta didik agar dapat meningkatkan Prestasi belajar pada Laznas Mizan Amanah.

2. Bagaimana memberikan pengetahuan kepada para peserta didik terhadap pentingnya membangun disiplin sejak dini untuk meningkatkan Prestasi Belajar.

3. Bagaimana memberikan pengarahan memalui memotivasi dan menumbuhkan semangat agar terbentuk karakter yang berdisiplin dalam rangka meningkatkan prestasi belajar.

\section{TUJUAN PELAKSANAAN}

Tujuan yang ingin dicapai dalam kegiatan pengabdian kepada masyarakat ini adalah sebagai berikut:

1.Mensosialisasikan kepada peserta didik pada Yayasan Laznas Mizan Amanah cara meningkatkan kedisiplinan .

2.Memotivasi peserta didik pada Yayasan Laznas Mizan Amanah agar menjadi siswa/i yang mampu meningkatkan prestasi belajar.

\section{TINJAUAN PUSTAKA}

Kedisiplinan berasal dari kata dasar disiplin, menurut Roswita dalam John (2011:13) Disiplin berasal dari bahasa Inggris discipline yang berarti "training to act accordance with rules," melatih seseorang untuk bertindak sesuai aturan. Menurut Unaradjan (2003:10) "disiplin diri adalah tingkah laku manusia yang terkontol, terkendali, serta teratur yang berpijak pada kesadaran dan maksud luhur dari pribadi yang bersangkutan agar keberadaannya selalu membahagiakan dirinya dan orang lain". Disiplin merupakan tingkah laku yang terkontrol dan kendali. Terkontrol dan kendali yang dimaksud yaitu mampu mengontrol dan mengendalikan diri dari perbuatan yang melanggar aturan.Kemudian pendapat lain menurut Fatimah (2011:53) bahwa "disiplin adalah merupakan aspek dari proses sosialisasi yang mengarahkan individu untuk memenuhi/mentaati apa yang diharapkan lingkungannya (keluarga, sekolah dan masyarakat) daripadanya". Kedisiplinan 
Loyalitas Kreativitas Aldi Masyarakat Kreatif merupakan aspek individu yang mengarahkan pada sikap untuk mentaati apa yang diharapkan lingkungannya, baik lingkungan keluarga, sekolah dan masyarakat. Dalam lingkungan keluarga kedisiplinan yang dimaksud yaitu dengan mentaati peraturan yang telah dibuat oleh keluarga. Dalam lingkungan sekolah kedisiplinan yang dimaksud yaitu dengan mentaati peraturan yang telah dibuat oleh sekolah. Sedangkandalam lingkungan masyarakat kedisiplinan yang dimaksud yaitu dengan mentaati peraturan yang telah dibuat oleh masyarakat.

Dari bebarapa teori yang dikemukakan oleh para ahli di atas maka dapat disimpulkan bahwa kedisiplinan adalah kesediaan untuk (taat, tunduk, nurut, patuh) pada aturan, norma-norma (baik norma agama maupun norma kesusilaan) baik yang tertulis maupun tidak tertulis, baik didalam lingkungan (keluarga, sekolah dan masyarakat), merupakan arahan untuk melatih dan membentuk seseorang untuk melakukan sesuatu menjadi lebih baik.

Kedisiplinan berasal dari kata dasar disiplin, menurut Roswita dalam John (2011:13) Disiplin berasal dari bahasa Inggris discipline yang berarti "training to act accordance with rules," melatih seseorang untuk bertindak sesuai aturan. Menurut Unaradjan (2003:10) "disiplin diri adalah tingkah laku manusia yang terkontol, terkendali, serta teratur yang berpijak pada kesadaran dan maksud luhur dari pribadi yang bersangkutan agar keberadaannya selalu membahagiakan dirinya dan orang lain".Disiplin merupakan tingkah laku yang terkontrol dan kendali. Terkontrol dan kendali yang dimaksud yaitu mampu mengontrol dan mengendalikan diri dari perbuatan yang melanggar aturan.Kemudian pendapat lain menurut Fatimah (2011:53) bahwa "disiplin adalah merupakan aspek dari proses sosialisasi yang mengarahkan individu untuk memenuhi/mentaati apa yang diharapkan lingkungannya (keluarga, sekolah dan masyarakat) daripadanya". Kedisiplinan merupakan aspek individu yang mengarahkan pada sikap untuk mentaati apa yang diharapkan lingkungannya, baik lingkungan keluarga, sekolah dan masyarakat. Dalam lingkungan keluarga kedisiplinan yang dimaksud yaitu dengan mentaati peraturan yang telah dibuat oleh keluarga. Dalam lingkungan sekolah kedisiplinan yang dimaksud yaitu dengan mentaati peraturan yang telah dibuat oleh sekolah. Sedangkandalam lingkungan masyarakat kedisiplinan yang dimaksud yaitu dengan mentaati peraturan yang telah dibuat oleh masyarakat.

Dari bebarapa teori yang dikemukakan oleh para ahli di atas maka dapat disimpulkan bahwa kedisiplinan adalah kesediaan untuk (taat, tunduk, nurut, patuh) pada aturan, norma-norma (baik norma agama maupun norma kesusilaan) baik yang tertulis maupun tidak tertulis, baik didalam lingkungan (keluarga, sekolah dan masyarakat), merupakan arahan untuk melatih dan membentuk seseorang untuk melakukan sesuatu menjadi lebih baik.

\section{HASIL DAN PEMBAHASAN}

Kami mengunjungi Mizan Amanah dan mengusulkan proposal yang telah kami buat agar kegiatan PKM dapat direalisasikan. Atas berbagai pertimbangan, akhirnya pimpinan Mizan Amanah, Cinere Depok memutuskan untuk memberikan izin kepada kami, Dosen Program Studi Sarjana Manajemen Universitas Pamulang, untuk dapat mengadakan sosialisasi dan pelatihan kepada peserta didik di Mizan Amanah, Cinere Depok

Adapun judul kegiatan PKM ini adalah "PENTINGNYA MENUMBUHKAN KEDISIPLINAN UNTUK MENINGKATKAN PRESTASI BELAJAR DI LEMBAGA AMIL ZAKAT NASIONAL MIZAN AMANAH (LAZNAS MIZAN AMANAH) CINERE". Judul ini kami anggap penting karena dalam menghadapi era globalisasi dibutuhkan peningkatan prestasi belajar siswa/i yang kreatif dan kompeten di bidangnya sehingga mampu melaksanakan tugas dan kewajibannya dengan baik dan maksimal. Dengan adanya sosialisasi dan pelatihan ini diharapkan dapat membawa dampak yang positif kepada Mizan Amanah pada umumnya dan para peserta didik pada khususnya agar semakin 
Loyalitas Kreativitas Aldi Masyarakat Kreatif
P-ISSN 2722-2101, E-ISSN 2722-4201

Program Studi Ekonomi Manajemen Universitas Pamulang Jurnal LOKABMAS Kreatif Vol.02,No.02.Juli 2021 Hal.62-67 Email:jurnalkreatif.manajemen@gmail.com termotivasi dalam meningkatkan prestasi belajarnya.

\section{KESIMPULAN DAN SARAN Kesimpulan}

Kegiatan Pengabdian Kepada Masyarakat (PKM) yang telah kami lakukan ini pada dasarnya adalah berkat kerjasama berbagai pihak terkait sehingga kegiatan dapat berjalan dengan baik dan terukur, serta materi yang kami sampaikan dapat bermanfaat bagi peserta didik pada Mizan Amanah. Dengan adanya kegiatan Pengabdian Kepada Masyarakat (PKM) ini, diharapkan peserta dapat mengaplikasikan ilmu yang telah mereka peroleh dalam kehidupan sehari-hari. Dan pada akhirnya, ilmu tersebut dapat dirasakan manfaatnya oleh peserta sendiri dan lingkungan di sekitarnya, khususnya lingkungan Mizan Amanah Cinere Depok

\section{Saran}

Saran kami terhadap Yayasan, dalam hal ini Mizan Amanah Cinere Depok, adalah hendaknya Yayasan lebih memperhatikan cara belajar siswa/i agar mereka lebih termotivasi dalam belajar, memfasilitasi pembelajaran dengan pelatihan (training) secara berkala tentang bagaimana meningkagtkan prestasi belajar peserta didik dan agar menjadi siswa/i yang kreatif untuk menghadapi kondisi dan situasi pembelajaran di era globalisasi seperti sekarang ini sehingga peserta didik semakin kompeten dalam melaksanakan tugas sesuai dengan tanggung jawabnya masing-masing dan memberikan dampak positif bagi kemajuan di masa yang akan datang..

\section{DAFTAR PUSTAKA}

Asmani, Jamal Ma'mur. 2009. Jurus-jurus Belajar Efektif Untuk SMP dan SMA.Jogjakarta:DIVA Press.

Herkusumu, Arniati Prasedyawati dkk. 2009. Hubungan Antara Pengaturan Diri Dalam Belajar, Selt Efficacy, Lingkungan Belajar Di Rumah, Dan Itelegensi Dengan Prestasi Belajar. Jurnal Keberbakatan dan Kreativitas Vol. 03. No. 01, Februari. Fakultas Psikologi Universitas Indonesia.
Krisnaldy, K., Pasaribu, V. L. D., \& Senen, S. (2019). Pengaruh Budaya Organisasi, Lingkungan Kerja Dan Iklim Organisasi Terhadap Motivasi Pegawai Serta Dampaknya Terhadap Kepuasan Kerja. Jurnal Semarak, 2(2), 164-183.

Krisnaldy, K., Pasaribu, V. L. D., \& Batubara, A. S. (2020). Analisis Pengaruh Kedisiplinan Terhadap Performa Pegawai Kelurahan Rempoa, Kota Tangerang Selatan. Jurnal Mandiri: Ilmu Pengetahuan, Seni, Dan Teknologi, 4(2), 131-138.

Manizar, E. (2015). Peran Guru Sebagai Motivator Dalam Belajar. 1(2), 204-222.

Pasaribu, V. L. D., Krisnaldy, K., \& Warasto, H. N. (2020). Pengaruh Gaya Kepemimpinan, Disiplin Kerja Dan Kompensasi Terhadap Kinerja Pegawai (Studi kasus kelurahan Pisangan Ciputat). Jurnal Disrupsi Bisnis: Jurnal Ilmiah Prodi Manajemen, Fakultas Ekonomi, Universitas Pamulang, 3(1).

Pasaribu, V. L. D., \& Krisnaldy, K. (2020). PENGARUH GAYA KEPEMIMPINAN, DISIPLIN KERJA DAN KOMPENSASI TERHADAP HASIL KINERJA KARYAWAN KELURAHAN PISANGAN CIPUTAT. PROCEEDINGS UNIVERSITAS PAMULANG, 1(1).

Ricardo, R., \& Meilani, R. I. (2017). Impak Minat dan Motivasi Belajar Terhadap Hasil Belajar Siswa. Jurnal Pendidikan Manajemen Perkantoran, 2 (2), 79.

Slameto. 2010. Belajar dan Faktor-faktor yang Mempengaruhinya. Jakarta:PT Rineka Cipta.

Sriyono, Heru. 2011. Program Bimbingan Untuk Membantu Meningkatkan Kemandirian Belajar Siswa. Jurnal SOSIO eKONS. Vol. III No.2 Mei-Juli. Jakarta: Universitas Indraprasta PGRI.

Suprayekti. 2010. Keterampilan Belajar Mahasiswa. Jurnal Perspektif Ilmu Pendidikan. Vol. 22 Th. XIII Oktober. 


\section{P-ISSN 2722-2101, E-ISSN 2722-4201}

Loyalitas Kreativitas Aldi Masyarakat Kreatif
Program Studi Ekonomi Manajemen Universitas Pamulang Jurnal LOKABMAS Kreatif Vol.02,No.02.Juli 2021 Hal.62-67

Email:jurnalkreatif.manajemen@gmail.com

Jakarta:Fakultas Ilmu Pendidikan Negeri Jakarta.

Umar Wirantasa (2017) Pengaruh Kedisiplinan Siswa terhadap Prestasi Belajar Mtematika. Jurnal formatif ISSN: 2088-351x

Yahdillah. (2019). Meningkatkan Kedisiplinan Siswa [Preprint].

https://guruppkn.com/cara-meningkatkandisiplin-belajar

\section{DOKUMENTASIKEGIATAN}
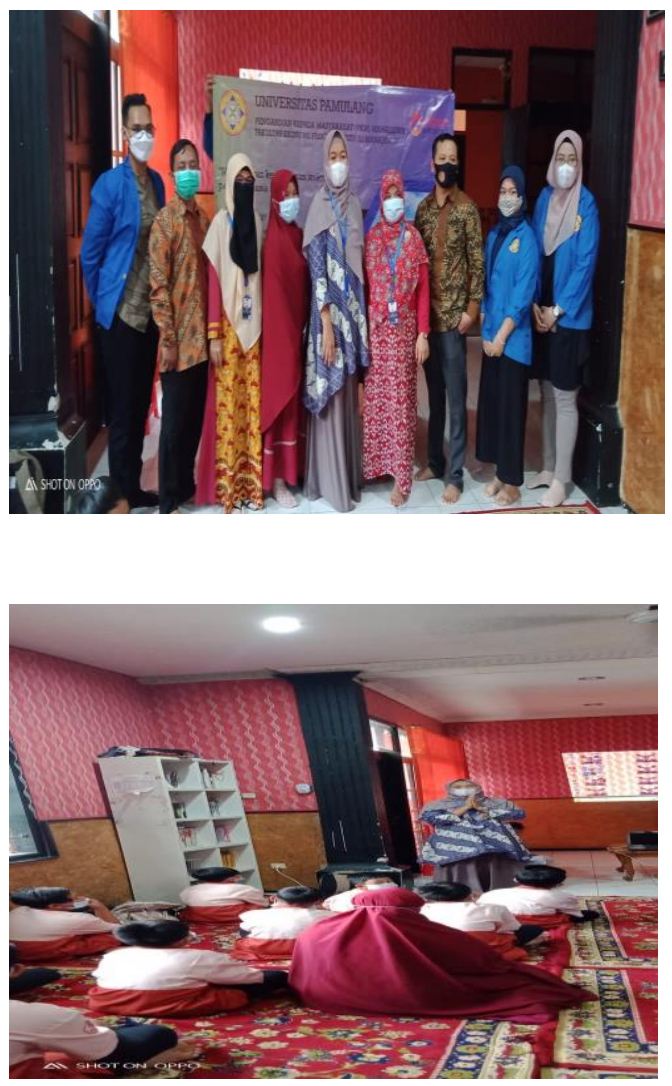